\title{
Analisis Kemampuan Merancang Rencana Pelaksanaan Pembelajaran pada Mahasiswa Pendidikan Sosiologi Fakultas Ilmu Sosial Universitas Negeri Padang
}

\author{
Melia Yulispa ${ }^{1}$, Junaidi Junaidi ${ }^{2}$ \\ ${ }^{1,2}$ Universitas Negeri Padang \\ Email: meliayulispa@gmail.com, junaidiunp@,fis.unp.ac.id.
}

\begin{abstract}
Abstrak
Salah satu kemampuan yang dituntut dalam pembelajaran adalah merancang RPP. Kenyataannya, RPP yang dibuat mahasiswa pendidikan sosiologi belum sepenuhnya sesuai dengan ketentuan. Penelitian bertujuan untuk melihat kemampuan merancang rencana pelaksanaan pembelajaran pada mahasiswa pendidikan sosiologi. Metode yang dipakai dalam penelitian ini adalah kualitatif dengan menggunakan tipe evaluatif. Hasil penelitian mengungkapkan bahwa kemampuan merancang RPP pada mahasiswa Pendidikan Sosiologi Fakultas Ilmu Sosial Universitas Negeri Padang, hal ini disebabkan oleh faktor internal dan faktor eksternal. (1) penyebab internal, terdiri dari (a) malas bertanya, (b) motivasi belajar rendah, (c) kebiasaan mencontoh pada teman/senior. (2) penyebab eksternal, terdiri dari (a) kontrol dosen dan jurusan (b) kemudahan akses internet. Hasil penelitian ini berguna sebagai pedoman dan masukan khususnya mahasiswa pendidikan sosiologi dalam merancang RPP agar sesuai dengan komponen RPP yang sudah ditentukan.
\end{abstract}

Kata kunci: Kemampuan, Merancang, Mahasiswa Pendidikan Sosiologi, RPP

\section{Abstract}

One of the abilities required in learning is designing lessons plans. In fact the lesson plans made by sociology education students are not yet fully in accordance with the provisions. This research aims to see the ability to design plans for implementing learning in sociology students. Thenmethod used in this research is qualitative by using evaluative type. The results of the study revealed that the ability to design plans in sociology education students at the faculty of social sciences padang state university was weak, this is caused by internal factors and external factors (1) internal causes consist of (a) lazy to ask, (b) low learning motivation (c) copying habits to friends or seniors. (2) external causes consist of (a) lecturer and department control (b) ease of internet access. The results of this study are useful as guidelines and input especially for sociology education students in designing lesson plan to fit the specified lesson plans.

Keywords: Ability, Design, Sociology Education, RPP

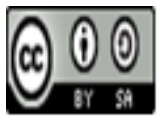

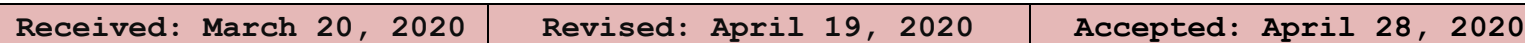

\section{Pendahuluan}

Perkembangan ilmu pengetahuan dan teknologi telah mengubah wajah peradaban dunia. Revolusi industri generasi ke empat (4.0) memiliki ciri khas berkembangnya teknologi yang semakin mutakhir, selain itu juga memiliki tantangan dan permasalahan. Hal yang paling fundamental adalah mengubah pola pikir dan sifat peserta didik dalam mengembangkan kemampuannya dalam menghadapi revolusi industri 4.0 sehingga dapat menjadi sumber daya manusia yang unggul (Sylvia, Anwar, \& Khairani, 2019). Pelaksana pendidikan khususnya pada pembelajaran adalah guru. Tanpa guru mustahil pembelajaran terlaksana dengan baik (Junaidi, 2018). Guru sebagai seorang pendidik memiliki syarat yang harus dipenuhi. Pendidik merupakan seseorang yang memiliki tanggung jawab untuk mendidik yang meliputi orang dewasa, orang tua, guru dan pemimpin agama (Reski, Junaidi, \& Fernandes, 2018). Tantangan guru abad 21 adalah harus memiliki kemamuan mempersiapkan peserta didik yang unggul dan memiliki kecakapan yang dibutuhkan di abad 21, yaitu adanya keterampilan 4C (Critical thingking, Communication, Collaborative, dan Creative) (Putra \& Nurlizawati, 2019). 
Oleh karena itu tugas guru yaitu mendesain, dan mengevaluasi pembelajaran secara efektif dan efisien. Sehingga nantinya dengan adanya kecakapan ini sebagai tambahan kecakapan akademik peserta didik akan terbantu dalam menyelesaikan permasalahan individual dan sosial yang dihadapi dalam kehidupan di lingkungannya (Sylvia et al., 2019).

Undang-undang Republik Indonesia No.14 Tahun 2005 tentang Guru Pasal 8 menyatakan guru harus mempunyai kemampuan akademik, sertifikat pendidik dan guru mampu mencapai tujuan pendidikan nasional. (Kemendikbud RI, 2005) Kemampuan mengembangkan perencanaan pembelajaran pada seorang pendidik dilihat dalam Permendiknas No 41 Tahun 2007 tentang Standar Proses Pembelajaran yaitu agar dapat mengembangkan RPP (Badan Standar Nasional Pendidikan, 2007). Pada Permendikbud tahun 2013 yang memuat mengenai perangkat pembelajaran dibuat dalam bentuk silabus dan RPP. Rencana pelaksanaan pembelajaran berguna sebagai pedoman dalam melaksanakan pembelajaran untuk mencapai kompetensi dasar (Marwa \& Fernandes, 2019). Keberhasilan pembelajaran yang dirancang dengan baik memerlukan perencanaan yang baik pula. Perencanaan yang dibuat menggambarkan kegiatan dari awal sampai akhir pembelajaran (Nadzir, 2013). Mahasiswa pendidikan sosiologi sebagai calon guru wajib untuk bisa merancang sebuah RPP, yang diajarkan melalui mata kuliah Perencanaan Pembelajaran Sosiologi pada semester lima. Sebagai calon guru mahasiswa pendidikan sosiologi harus mempunyai kemampuan dalam merancang perangkat pembelajaran khususnya RPP. Kenyataannya kemampuan mahasiswa pendidikan sosiologi dalam merancang komponen RPP yang sesuai dengan komponen yang sudah ditentukan masih lemah. Artikel ini mengungkapkan kemampuan merancang RPP pada mahasiswa pendidikan sosiologi.

Penelitian yang sudah dilakukan oleh Fatiyatul Istiqomah yaitu tentang Analisis Kemampuan Menyusun RPP Kurikulum 2013 pada Mahasiswa Pendidikan Kimia FKIP Universitas Tanjungpura (Istiqomah, 2018). Data yang peneliti dapatkan dari RPP mahasiswa pendidikan sosiologi menunjukkan bahwa terdapat komponen yang kurang sesuai dengan format komponen RPP yang ada di dalam Permendikbud no 22 Tahun 2016. Seharusnya dalam pembuatan RPP mahasiswa harus memperhatikan pentingnya RPP yang baik dan benar agar dapat dijadikan sebagai panduan jika mahasiswa akan melaksanakan praktek menjadi guru nantinya. Kesamaan penelitian ini dengan penelitian yang peneliti lakukan yaitu sama-sama membahas kemampuan menyusun RPP kurikulum 2013. Akan tetapi, juga terdapat perbedaan dalam penelitian ini. Peneliti disini membahas tentang analisis kemampuan merancang rencana pelaksanaan pembelajaran pada mahasiswa Pendidikan Sosiologi FIS UNP. Dengan batasan masalahnya yaitu mahasiswa pendidikan sosiologi tahun masuk 2016 yang rancangan RPP nya kurang sesuai dengan kurikulum 2013. Serta, tujuan penelitian ini adalah mengetahui kemampuan merancang RPP sosiologi SMA pada mahasiswa Pendidikan Sosiologi Fakultas Ilmu Sosial Universitas Negeri Padang.

\section{Metode Penelitian}

Di dalam penelitian ini metode yang digunakan adalah pendekatan kualitatif (Sugiyono, 2009). Tipe penelitian ini adalah penelitian evaluatif. Penelitian evaluatif berguna untuk mengetahui tingkat keberhasilan dan keefektifan program tertentu (Usman \& Akbar, 2009). Penelitian ini dilakukan di Jurusan Sosiologi Fakultas Ilmu Sosial Universitas Negeri Padang. Alasan peneliti memilih Jurusan Sosiologi adalah karena peneliti yang memiliki pengalaman dan pemahaman mengenai kondisi perkuliahan pada saat perencanaan pembelajaran sosiologi di semester lima. Teknik yang dilakukan adalan teknik purposive sampling yaitu teknik ini mempertimbangkan informan berdasarkan tujuan-tujuan tertentu dengan jumlah informan adalah 13 orang diantaranya terdiri dari 2 orang dosen Jurusan Sosiologi dan 11 orang mahasiswa Pendidikan Sosiologi. Teknik pengumpulan data melalui wawancara dan dokumentasi. Keabsahan data diuji menggunakan triangulasi sumber dan triangulasi teknik (Gulo, 2000), dan data dianalisis dengan teknik yang dikembangkan oleh Miles dan Huberman.

Jurnal Sikola: Jurnal Kajian Pendidikan dan Pembelajaran Vol. 1, No. 4, Th. 2020 


\section{Hasil dan Pembahasan}

Kemampuan merancang RPP merupakan suatu kegiatan yang harus dikuasai oleh seorang mahasiswa calon guru sosiologi. Hal ini bertujuan agar pembelajaran dapat tercapai nantinya secara efisisen dan efektif. Hasil pemahaman mahasiswa Pendidikan Sosiologi Fakultas Ilmu Sosial Universitas Negeri Padang dalam merancang RPP masih lemah. Dari hasil wawancara dengan informan disimpulkan bahwa mahasiswa dalam merancang RPP lemah disebabkan oleh penyebab internal seperti malas bertanya, moivasi belajar rendah, dan kebiasaan mencontek pada teman/senior. Sedangkan penyebab eksternalnya adalah kontrol dosen dan jurusan dan kemudahan akses internet. Berikut tabel yang mengungkapkan pemahaman mahasiswa pendidikan sosiologi dalam memahami sebuah RPP

\section{Tabel 1. Rancangan RPP Menurut Kurikulum 2013 dan Rancangan RPP Mahasiswa Pendidikan Sosiologi FIS UNP}

\begin{tabular}{|c|c|c|}
\hline No & $\begin{array}{c}\text { Rancangan RPP menurut } \\
\text { Kurikulum } 2013 \\
\end{array}$ & Temuan RPP Hasil Rancangan Mahasiswa \\
\hline 1 & Kelengkapan identitas sekolah & Sudah ditemukan adanya kelengkapan identitas sekolah \\
\hline 2 & $\begin{array}{l}\text { Kelengkapan identitas mata } \\
\text { pelajaran }\end{array}$ & $\begin{array}{l}\text { Untuk identitas mata pelajaran pada RPP yang dirancang oleh } \\
\text { mahasiswa pendidikan sosiologi sudah ditemukan adanya } \\
\text { kelengkapan identitas mata pelajaran }\end{array}$ \\
\hline 3 & Kelas/semester & Kelas/semester sudah ada \\
\hline 4 & Materi pokok & Sudah ada \\
\hline 5 & Alokasi waktu & $\begin{array}{l}\text { Pada rancagan RPP mahasiswa pendidikan sosiologi untuk } \\
\text { alokasi waktu mahasiswa menulisnya bervariasi seperti } 2 \mathrm{JP} \\
\text { dan ada juga yang menuliskan } 2 \times 45 \text { menit }\end{array}$ \\
\hline 6 & Tujuan pembelajaran & $\begin{array}{l}\text { Pada RPP yang dirancang mahasiswa pendidikan sosiologi di } \\
\text { bagian tujuan pembelajaran ada yang tidak memuat } \\
\text { pendekatan, metode pembelajaran, dan strategi pembelajaran } \\
\text { apa yang harusnya digunakan serta ada yang tidak } \\
\text { menggunakan KKO }\end{array}$ \\
\hline 7 & $\begin{array}{l}\text { Kompetensi dasar dan indikator } \\
\text { pencapaian kompetensi }\end{array}$ & $\begin{array}{l}\text { Pada RPP mahasiswa dalam merancang KD dan IPK sering } \\
\text { mengulang kata kerja yang sama untuk setiap sub-sub } \\
\text { materinya }\end{array}$ \\
\hline 8 & Materi pembelajaran & $\begin{array}{l}\text { Temuan pada RPP mahasiswa di bagian materi pembelajaran } \\
\text { sering terdapat ketidaksesusaian antara fakta dan prinsip. }\end{array}$ \\
\hline 9 & Metode pembelajaran & $\begin{array}{l}\text { Pada RPP mahasiswa belum ditemukan metode pembelajaran } \\
\text { yang bervariasi. }\end{array}$ \\
\hline 10 & Media pembelajaran & $\begin{array}{l}\text { Pada RPP yang dirancang mahasiswa pendidikan sosiologi } \\
\text { penggunaan alat/media hanya menggunakan papan tulis, } \\
\text { spidol dan penghapus seharusnya dapat ditambahkan dengan } \\
\text { media lainnya guna tercapainya pembelajaran yang kreatif. }\end{array}$ \\
\hline 11 & Sumber belajar & $\begin{array}{l}\text { Pada RPP yang dirancang mahasiswa pendidikan sosiologi } \\
\text { sudah memuat ketentuan dalam kurikulum } 2013 \text { seperti } \\
\text { penggunaan buku paket, laptop, dan internet. }\end{array}$ \\
\hline 12 & Langkah-langkah pembelajaran & $\begin{array}{l}\text { Pada RPP yang dirancang mahasiswa pendidikan sosiologi di } \\
\text { bagian pendahuluan seharusnya memuat berdoa berdasarkan } \\
\text { keyakinan masing-masing namun tidak dituliskan. Pada } \\
\text { bagian inti tidak memuat pembelajaran HOTS, dan pada } \\
\text { bagian penutup tidak dituliskan nilai karakter religiusnya. }\end{array}$ \\
\hline 13 & Penilaian hasil pembelajaran & $\begin{array}{l}\text { Pada RPP yang dirancang mahasiswa pendidikan sosiologi } \\
\text { tidak tersusun dengan jelas instrumen penilaian sikap, } \\
\text { pengetahuan dan keterampilan. }\end{array}$ \\
\hline
\end{tabular}


Berdasarkan RPP yang sudah dirancang oleh mahasiswa pendidikan sosiologi terdapat beberapa komponen RPP yang belum dipahami secara maksimal oleh beberapa mahasiswa sehingga menyebabkan RPP yang dirancang belum sesuai dengan ketentuan yang ada pada kurikulum 2013. Kelemahan merancang tersebut terletak pada komponen RPP yaitu (1) alokasi waktu pembelajaran. (2) Merumuskan KD dan IPK. (3) Menentukan tujuan pembelajaran. (4) Menjabarkan materi pembelajaran (5) Menyesuaikan metode pembelajaran (6) Menentukan media pembelajaran (7) Menyusun langkah-langkah pembelejaran dan (8) Menuliskan penilaian hasil pembelajaran. Namun, juga terdapat beberapa komponen RPP yang sudah dipahami mahasiswa seperti identitas sekolah, mata pelajaran dan sumber pembelajaran. Berikut tabel kesesuaian RPP yang dirancang dengan komponen RPP yang sudah ditentukan dalam kurikulum 2013.

\section{Tabel 2. Kesesuaian RPP yang dirancang dengan Komponen RPP yang sudah di dientukan} dalam Kurikulum 2013.

\begin{tabular}{clcc}
\hline No & \multicolumn{1}{c}{ Aspek RPP menurut Kurikulum 2013 } & \multicolumn{2}{c}{ Kesesuaian RPP Mahasiswa } \\
\cline { 3 - 4 } & & Sesuai & Belum Sesuai \\
\hline 1 & Kelengkapan identitas sekolah & $\checkmark$ & \\
\hline 2 & Kelengkapan identitas mata pelajaran & $\checkmark$ & \\
\hline 3 & Kelas/semester & $\checkmark$ & \\
\hline 4 & Materi pokok & & $\checkmark$ \\
\hline 5 & Alokasi waktu & & $\checkmark$ \\
\hline 6 & Tujuan pembelajaran & \\
\hline 7 & Kompetensi dasar dan indikator pencapaian kompetensi & $\checkmark$ \\
\hline 8 & Materi pembelajaran & & $\checkmark$ \\
\hline 9 & Metode pembelajaran & $\checkmark$ & $\checkmark$ \\
\hline 10 & Media pembelajaran & & $\checkmark$ \\
\hline 11 & Sumber belajar & & \\
\hline 12 & Langkah-langkah pembelajaran & \\
\hline 13 & Penilaian hasil pembelajaran & & \\
\hline
\end{tabular}

Dari tabel di atas dapat disimpulkan bahwa mahasiswa pendidikan sosiologi belum sepenuhnya memiliki kecakapan dalam merancang rencana pelaksanaan pembelajaran karena belum sepenuhnya rancangan RPP yang dibuat sesuai dengan ketentuan yang ada di dalam kurikulum 2013, karena terdapat ada beberapa komponen di dalam RPP yang belum sesuai, yaitu alokasi waktu, tujuan pembelajaran, kompetensi dasar dan indikator pencapaian kompetensi, materi pembelajaran, metode pembelajaran, media pembelajaran.

Idealnya mahasiswa pendidikan sosiologi harus bisa merancang rencana pelaksanaan pembelajaran sesuai dengan ketentuan yang ada di dalam kurikulum 2013, namun berdasarkan pengamatan dan wawancara dengan informan disimpulkan lemahnya kemampuan mahasiswa dalam merancang rencana pelaksanaan pembelajaran disebabkan oleh dua faktor yaitu penyebab internal dan penyebab eksternal.

Kemampuan mahasiswa pendidikan sosiologi dalam merancang perangkat pembelajaran khususnya RPP masih lemah, diketahui bahwa kurang maksimalnya kemampuan mahasiswa diatas disebabkan oleh beberapa hal. Berdasarkan penelitian penyebab tersebut diklasifikasikan atas dua yaitu faktor internal dan eksternal. Penyebab internal yang menjadi penyebab lemahnya kemampuan merancang RPP pada mahasiswa Pendidikan Sosiologi FIS UNP (a) malas bertanya, pembelajaran dapat berlangsung dengan baik jika berjalan dua arah, dosen tidak hanya ditugaskan sebagai penceramah dalam memberikan materi di depan kelas, mahasiswa harus aktif dan bertukar pendapat dengan dosen di dalam kelas, untuk melakukan hal itu mahasiswa harus bertanya dalam proses perkuliahan. Teori belajar Behavioristik yang dicetuskan oleh Gage dan Berliner menurut pandangan teori ini yang terpenting adalah masukan atau input yang berupa 
stimulus dan keluaran atau output yang berupa respons dan oleh sebab itu apa saja yang diberikan guru (stimulus) dan apa yang dihasilkan peserta didik (respons) semuanya dapat diamati dan diukur. (Rachmawati, 2015).

Pada saat perkuliahan perencanaan pembelajaran sosiologi dosen memberikan input atau stimulus berupa cara pembuatan RPP untuk setiap kali tatap muka, agar mahasiswa dapat membuat RPP dengan baik dan benar, namun respons mahasiswa pendidikan sosiologi malas untuk bertanya, hal ini tentunya akan menyebabkan input yang diberikan dosen tidak akan tersampaikan dengan baik karena mahasiswa tidak mengerti namun malas untuk bertanya, dan mahasiswa juga hanya mengandalkan teman apabila sudah ada yang bertanya satu atau dua orang maka yang lain hanya mengikuti teman yang sudah bertanya, sedangkan diri mereka sendiri belum mengerti.(b) motivasi belajar rendah, Teori Contiguity dari Edwin R. Guthrie dikenal dengan nama teori Contiguous Conditioning. Berdasarkan teori Contiguity dari Guthrie, individu mempunyai kapasitas belajar yang berbeda, yang dapat dilihat melalui penyebab/alasan individu dalam merespons sesuatu (Rachmawati, 2015).

Motivasi dalam belajar menurut Guthrie mempengaruhi hasil belajar pada setiap individu. RPP merupakan salah satu bentuk hasil belajar dari proses perkuliahan perencanaan pembelajaran sosiologi di semester lima. RPP yang di rancang oleh mahasiswa pendidikan sosiologi tidak sesuai dengan komponen yang ditentukan disebabkan oleh alasan mahasiswa pendidikan sosiologi pada saat perkuliahan, motivasi mahasiswa pendidikan sosiologi untuk belajar itu rendah, karena mereka sudah tidak mengerti dari awal dan tidak ada bertanya. Mahasiswa pendidikan sosiologi sering mengambil jalan instan untuk mempermudah dirinya.RPP tersebut dijadikan sebagai pemenuhan tugas dengan tujuan untuk sekedar dikumpulkan. Sebagai salah satu jurusan yang berasal dari prodi pendidikan, lulusan yang diharapkan tentunya calon pendidik yang mengerti tata cara merancang sebuah RPP yang baik dan benar, maka dari itu motivasi belajar mahasiswa pendidikan sosiologi harus tinggi, agar perkuliahan kedepannya dapat berjalan dengan efektif. (c) kebiasaan mencontoh pada teman/senior, kebiasaan merupakan suatu aktivitas yang dilakukan secara berulang. Aktivitas yang dilakukan berulang-ulang dapat berupa aktivitas yang baik maupun buruk. Mencontek merupakan salah satu kegiatan plagiat yang sangat di larang terutama jika seseorang telah duduk di perguruan tinggi.

Pada proses perkuliahan tentunya mahasiswa memiliki banyak teman ataupun senior yang lebih dahulu menempuh pendidikan pada jurusan yang sama. Teori Systematic Behavior dari Clark L. Hull (1884-1952), tentang kebiasaan, kebiasaan merupakan perilaku kompleks diasumsikan dari hasil dan bentuk perilaku belajar yang sederhana. Menurutnya, individu dapat mempengaruhi interaksi antara stimulus dan respons. Proses tersebut disebut sebagai variabel "intervening" (yang berpengaruh) (Rachmawati, 2015). Menurut teori Hull kondisi ini terjadi karena adanya pengaruh melalui interaksi antar individu. Kebiasaan mencontek RPP dari teman dan senior merupakan suatu hal yang dilakukan sengaja karena RPP diperlukan untuk mengumpulkan tugas akhir perkuliahan, senior dan teman disini merupakan pihak yang paling berpengaruh yang menjadi sarana penyedia yang tepat namun, tidak pasti hasilnya akan benar.

Sedangkan untuk penyebab eksternal yang menyebabkan lemahnya kemampuan mahasiswa pendidikan sosiologi dalam merancang RPP yaitu (a) kontrol dosen dan jurusan, setiap dosen memberikan tugas sesuai mata kuliah yang diampunya. Proses perkuliahan di Universitas Negeri Padang memperbolehkan dan menyarankan penggunaan bahan ajar atau sarana prasarana berbasis internet termasuk smartphone. Kondisi ini tentu berpengaruh terhadap perkuliahan mahasiswa terutama mempengaruhi cara dan perilaku belajar mahasiswa yang kecanduan smartphone (Febrian \& Sylvia, 2019). Kebiasaan mahasiswa sering menggunakan cara instant untuk memperoleh nilai di Perguruan Tinggi. Teori Operant Conditioning dari B.F. Skinner, menurut teori Skinner respons sangat tergantung kepada penguatan yang dilakukan secara berulang-ulang. Kegiatan pembelajaran peserta didik menekankan pada hasil jawaban yang benar (Rachmawati, 2015). Kontrol dosen dan jurusan sangat berpengaruh besar pada 
mahasiswa pendidikan sosiologi, dosen yang mengajar perencanaan pembelajaran sosiologi di semester lima harus memberikan penguatan berulang-ulang mengenaitata cara merancang sebuah RPP. (b) kemudahan akses internet,Kemajuan ilmu pengetahuan dan teknologi membuat segala kebutuhan manusia menjadi lebih mudah. Hal yang sama juga dapat dilakukan oleh mahasiswa pendidikan sosiologi dalam menggunakan jaringan internet.Teori Belajar dari David Ausubel dikenal dengan Teori Belajar Bermakna atau Meaningful Learning belajar bermakna akan terjadi apabila informasi yang baru berkaitan erat dengan konsep yang diterima sebelumnya dan tersimpan dalam kesadaranindividu (Rachmawati, 2015).

Mahasiswa pendidikan sosiologi dalam merancang RPP menggunakan internet sebagai salah satu langkah cepat untuk dapat menyelesaikan tugas mereka, internet dapat dijadikan sebagai sumber informasi/sumber pengetahuan baru bagi mahasiswa pendidikan sosiologi. Namun hal ini tidak dapat diwujudkan karena mahasiswa pendidikan sosiologi pada saat perkuliahan perencanaan pembelajaran sosiologi tidak mengerti bagaimana merancang komponen RPP yang sesuai dengan komponen RPP yang sudah ditentukan, konsep belajar RPP tidak dapat dihubungkan dengan informasi baru yang di dapat dari internet.Kemudahan inilah yang memicu mahasiswa pendidikan sosiologi menyalahgunakan akses internet untuk mencari RPP yang sudah jadi karena semua RPP di internet sudah tersedia lengkap dengan seluruh komponennya.

Secara umum kemampuan mahasiswa pendidikan sosiologi dalam merancang RPP di pengaruhi oleh dua faktor yaitu internal dan eksternal. Jika dianalisis menggunakan Teori Belajar menurut Robert M.Gagne proses penerimaan informasi dalam bentuk hasil belajar. Kondisi internal menurut Gagne adalah keadaan pada diri individu untuk mencapai hasil belajar dan proses belajar kognitif. Kondisi internal yang terjadi pada mahasiswa pendidikan sosiologi meliputi keadaan; malas bertanya, motivasi belajar rendah dan kebiasaan mencontek pada teman/senior.Keadaan ini terjadi karena dorongan dari masing-masing diri mahasiswa pendidikan sosiologi. Kondisi eksternal menurut Gagne adalah rangsangan dari lingkungan yang mempengaruhi individu pada saat pembelajaran.

Kondisi eksternal menurut Gagne disebut sebagai sembilan peristiwa pembelajaran. (1) memberikan perhatian, perhatian lebih dari dosen disini perlu diberikan kepada mahasiswa pendidikan sosiologi agar mahasiswa dalam proses perkuliahannya dapat lebih termotivasi. (2) memberi tahu tujuan pembelajaran, dosen disini mendeskripsikan kepada mahasiswa pendidikan sosiologi sebagai calon pendidik masa depan sehingga mereka harus paham merancang sebuah RPP. (3) dibangun atas pengetahuan yang telah lalu. (4) pembelajaran sebagai rangsangan. (5) memberikan panduan belajar, dosen harus aplikatif dalam memberikan panduan mahasiswa pendidikan sosiologi dalam membuat RPP, agar mereka dapat berpikir kreatif. (6) menampilkan kinerja, RPP untuk lebih efektifnya dosen dapat menyuruh mahasiswa membuat komponen RPP yang tidak ia mengerti di depan kelas pada saat proses pembelajaran, lalu membahasnya secara bersama-sama (7) memberikan umpan balik. (8) menilai kinerja, RPP yang sudah dikumpulkan biasanya ditandatangani dan diberi nilai oleh dosen, nilai yang diberikan biasanya dapat dilihat pada portal akademik pada saat akses nilai sudah bisa dibuka, cara lain yang dapat digunakan agar mahasiswa pendidikan sosiologi merancang sebuah RPP dengan baik dan tidak mencontek RPP dari teman atau senior dengan cara setelah RPP dikumpulkan di akhir semester dinilai oleh dosen dikembalikan lagi kepada mahasiswa terutama RPP yang terdapat copy paste dituliskan RPP tersebut sama dengan RPP siapa. Jika mahasiswa pendidikan sosiologi telah tahu dimana letak kesalahannya, maka ia tidak akan mengulanginya. (9) meningkatkan ingatan dan transfer pengetahuan, dosen dalam perkuliahan membantu mahasiswa pendidikan sosiologi dalam mengingat-ingat perkuliahan sebelumnya guna tidak tertimpa oleh pengetahuan baru.

Seharusnya mahasiswa Pendidikan Sosiologi sebagai calon pendidik harus mampu merancang sebuah RPP dengan baik dan benar, namun kenyataannya mahasiswa pendidikan sosiologi masih lemah dalam merancang sebuah RPP berdasarkan wawancara dengan informan lemahnya kemampuan tersebut disimpulkan karena faktor internal dan ekternal. Pada 
pengamatan yang peneliti lakukan terhadap RPP yang dirancang oleh mahasiswa Pendidikan Sosiologi Fakultas Ilmu Sosial Universitas Negeri Padang belum sepenuhnya sesuai dengan RPP yang sudah ditentukan dalam kurikulum 2013, sebagai seorang pendidik mahasiswa Pendidikan Sosiologi perlu maksimal dalm merancang sebuah RPP. Setiap orang memiliki hak untuk mengembangkan diri dengan memenuhi kebutuhan dasar, hak untuk mendapatkan pendidikan, untuk mendapat manfaat dari ilmu pengetahuan dan teknologi, seni dan budaya dalam rangka meningkatkan kualitas hidup (Mulyaningsih, Nuryana, Sylvia, Casmudi, \& Haluti, 2019). Oleh karena itu hasil penelitian ini perlu mendapatkan perhatian serius agar mahasiswa dapat memenuhi kompetensi lulusan sebagai calon guru Sosiologi.

\section{Kesimpulan}

Penelitian ini mendapatkan hasil bahwa kemampuan merancang RPP pada mahasiswa pendidikan sosiologi FIS UNP masih lemah. Kelemahan merancang tersebut terletak pada komponen RPP yaitu (1) alokasi waktu pembelajaran. (2) Merumuskan KD dan IPK. (3) Menentukan tujuan pembelajaran. (4) Menjabarkan materi pembelajaran (5) Menyesuaikan media pembelajaran (6) Menentukan metode pembelajaran (7) Menyusun langkah pembelajaran dan (8) Menuliskan penilaian hasil pembelajaran.

Lemahnya mahasiswa pendidikan sosiologi dalam merancang RPP peneliti menemukan tiga penyebab internal dan dua penyebab eksternal. Penyebab internal yang terdiri dari: (1) Malas Bertanya, disebabkan karena mereka yang kurang/tidak memahami penjelasan yang diberikan dosen pada saat perkuliahan perencanaan pembelajaran sosiologi di semester lima (2) Motivasi Belajar Rendah, dikarenakan mereka sudah tidak mengerti dari awal dan tidak ada bertanya. (3) Kebiasaan Mencontoh pada Teman/Senior, merupakan suatu hal yang dilakukan sengaja karena RPP diperlukan untuk mengumpulkan tugas akhir perkuliahan, teman dan senior menjadi sarana penyedia yang tepat namun, tidak pasti hasilnya akan benar. Sementara itu penyebab eksternal terdiri dari: (1) Kontrol Dosen dan Jurusan, diperlukan agar membantu mahasiswa dalam merancang RPP yang baik dan benar (2) Kemudahan Akses Internet, memudahkan mahasiswa pendidikan sosiologi untuk memilih jalan instan menyelesaikan tugas yaitu dengan cara mencari sendiri di internet dan melakukan copy paste guna memenuhi tugas akhir yang diberikan.

\section{Daftar Pustaka}

Badan Standar Nasional Pendidikan. (2007). Peraturan Menteri Pendidikan Nasional Republik Indonesia Nomor 41 Tahun 2007 Tentang Standar Proses untuk Satuan Pendidikan dasar dan Menengah. Jakarta.

Febrian, R., \& Sylvia, I. (2019). Perilaku Belajar Mahasiswa Pecandu Smartphone di Jurusan Sosiologi FIS UNP. Jurnal Perspektif, 2(4), 456-465. https://doi.org/10.24036/ perspektif.v2i4.110

Gulo, W. (2000). Metodologi Penelitian. Jakarta: PT Grasindo.

Istiqomah, F. (2018). Analisis Kemampuan Menyusun RPP Kurikulum 2013 Pada Mahasiswa pendidikan Kimia FKIP Universitas Tanjungpura. Jurnal Pendidikan dan Pembelajaran Katulistiwa, 7(9), 1-13.

Junaidi, J. (2018). Sumber Belajar dalam Membelajarkan Sosiologi. Diambil dari Universitas Negeri Padang website: https://osf.io/preprints/inarxiv/93zca/

Kemendikbud RI. (2005). Undang-Undang Republik Indonesia Nomor 14 Tahun 2005 Tentang Guru dan Dosen. Jakarta: Kemendikbud RI.

Marwa, Y. Y., \& Fernandes, R. (2019). Penerapan Rencana Pelaksanaan Pembelajaran dalam Pembelajaran Sosiologi (Studi Kasus SMAN 3 Painan dan SMAN 2 Bayang). Sikola, 1(1), 14-19. https://doi.org/https://doi.org/10.24036/sikola.v1i1.2 
Mulyaningsih, I., Nuryana, Z., Sylvia, I., Casmudi, C., \& Haluti, F. (2019). Addressing the Blockages of Education and Culture Development. Test Engineering and Management, 81(1102), 1102-1106.

Nadzir, M. (2013). Perencanaan Pembelajaran Berbasis Karakter. Jurnal Pendidikan Agama Islam (Journal of Islamic Education Studies), 1(2), 338-352.

Putra, D. M., \& Nurlizawati, N. (2019). Lesson Study dalam Meningkatkan Keterampilan 4C (Critical Thingking, Collaborative, Communicative dan Creative) pada Pembelajaran Sosiologi yang Terintegrasi ABS-SBK di SMAN 1 Pasaman. Sikola, 1(2), 139-146. https://doi.org/https://doi.org/10.24036/sikola.v1i2.19

Rachmawati, T. \& daryanto. (2015). Teori Belajar dan Proses Pembelajaran yang Mendidik. Yogyakarta: Gava Media.

Reski, Y., Junaidi, J., \& Fernandes, R. (2018). Faktor Pendorong Anak Nelayan Di Desa Naras I Melanjutkan Pendidikan ke Jenjang SLTA. Jurnal Perspektif, 1(4), 44-50. https://doi.org/http://dx.doi.org/10.24036/perspektif.v1i4.50

Sugiyono. (2009). Metode Penelitian Kuantitatif, Kualitatif, Dan R\&D. Bandung: Alfabeta.

Sylvia, I., Anwar, S., \& Khairani, K. (2019). Pengembangan Instrumen Penilaian Autentik Berbasis Pendekatan Authentic Inquiry Learning Pada Mata Pelajaran Sosiologi di Sekolah Menengah Atas. Socius, 6(2), 103-120. https://doi.org/10.24036/scs.v6i2.162

Usman, H., \& Akbar, P. S. (2009). Metodologi Penelitian Sosial. Jakarta: PT Bumi Aksara. 